\title{
AUTOR:
}

ReNATA LOPES BRITTO

ORIENTADORA:

\section{Terapia hormonal com implantes de estradiol e testosterona: proteção óssea?}

Profa. Dra. lella Maria Batista Araújo

\author{
Hormonal therapy with estradiol and testosterone implants: bone protection
}

Resumo de tese

Palavras-chave

Pós Menopausa Terapia Hormonal Densidade mineral óssea Implantes subdérmicos

Testosterona

Osteoporose

Keywords

Postmenopause Hormone therapy Bone mineral density Subdermal implants Testosterone Osteoporosi
Tese apresentada ao Programa de Pós Graduação em Medicina e Saúde da Faculdade de Medicina da Universidade Federal da Bahia, para obtenção do título de Mestre, em 29 de outubro de 2009.

OBJETIVO: avaliar a densidade Mineral Óssea (DMO) entre as usuárias de implantes hormonais de Estradiol e Testosterona comparando com pacientes sem Terapia Hormonal. MÉTODOS: estudo de Coorte Prospectivo com 61 pacientes separadas em grupo 1, usuárias de implantes de Estradiol e Testosterona e grupo 2, não usuárias de implantes, com avaliação de DMO através de densitometria mineral óssea de dupla energia (DEXA), realizadas no início do seguimento e após 1 ano. RESULTADOS: a DMO média na coluna lombar no grupo 1 foi de $1,12 \pm 0,16 \mathrm{~g} / \mathrm{cm}^{2}$ e passou a $1,14 \pm 0,18$

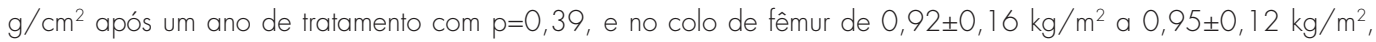

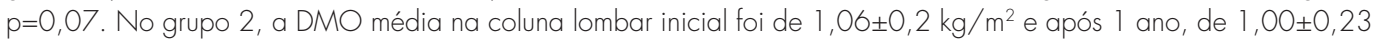

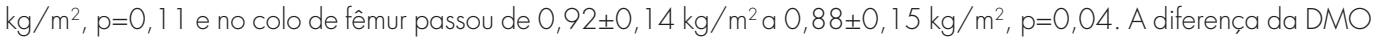
na coluna lombar e colo de fêmur entre os grupos no inicio do estudo não foi estatisticamente significante, com $p=0,2$ e $p=0,8$ respectivamente. Após 1 ano de tratamento houve diferença estatisticamente significante na DMO entre os dois grupos, com $\mathrm{p}=0,01$ para coluna lombar e $\mathrm{p}=0,04$ para colo de fêmur. CONCLUSÃO: as pacientes usuárias de implantes de estradiol e testosterona apresentaram ganho de massa óssea enquanto as não usuárias perderam massa óssea após 1 ano de acompanhamento. A variação da DMO entre os grupos no período de um ano mostrou que a combinação Estradiol e Testosterona exerce proteção óssea nas pacientes. 